\title{
A Curriculum Unit for Promoting Complex System Thinking: The Case of Combined System Dynamics and Agent Based Models for Population Growth
}

\author{
Billie Eilam and Dorit Reisfeld \\ Faculty of Education, University of Haifa, Israel \\ Email: beilam@edu.haifa.ac.il
}

\begin{abstract}
Calls for school curricula to increase students' exposure to complex systems are clearly warranted, given the topic's learnability and the increasing prevalence of such systems. This study deepens our understanding of 16 ninth graders' system thinking by identifying some cognitive aspects involved in the acquisition process while studying specially designed simulation-based curriculum for a full semester. Students manipulated two simulation-types: (a) providing a top-down view of the system behavior - based on the system dynamics model, and (b) providing a bottom-up view of the same system - based on the agent-based model. Contrasting these simulation outputs scaffold students' ability to relate the system macro and micro levels. We focused on complex system conceptual knowledge (dynamic equilibrium) and diverse system thinking modes (stochastic or dynamic thinking) by examining students' written and computerized products and pre-posttests results. A significant improvement in most students' system thinking abilities has been found. Implications for school science instruction are discussed.
\end{abstract}

Keywords: Complex systems; system thinking; ecology; agent-based and system dynamics models; cognitive aspects; junior-high school

\section{Introduction}

High-order system thinking has been shown to involve many difficulties, such as those related to the system's multi levels, component interactions, dynamicity, or equilibrium (AUTHOR, 2012; Levy \& Wilensky, 2008; Wilensky \& Reisman, 2006). Vachliotis Salta and Tzougraki (2014) contend that "Much of the research to date suggests that only through carefully designed educational interventions, do individuals come to understand complex phenomena" (p. 3). Although studies show that students from the middle school can learn the topic and benefit from it (Jacobson \& Wilensky, 2006) and some related instructional remedies have been suggested (Ben-Zvi \& Orion, 2010; Chi, 2005; Hmelo-Silver \& Pfeffer, 2004), a unified conceptual framework for the development of system thinking in school is still absent from most schools' curricula (Draper, 1993; Jacobson \& Wilensky, 2006).

In this study, we respond to present calls for introducing systems thinking into school curricula, by designing a pilot novel curriculum unit that aims to confront the core system characteristic - the system interrelated micro and macro levels - identified as impeding system understanding. Students' comprehension of the system levels was assessed via their definitions, task responses and use of the complex concept of dynamic equilibrium. Learning the unit is simulation-based, responding to complementary calls for model-based science teaching (Bucklet et al., 2004). Two kinds of simulations have been proposed for promoting students' system thinking: the system dynamics based simulation (SD) that represents the macro level of the system through a top-down approach and the agent-based (AB) simulations that represent the micro level of the system through a bottom up approach (Norling, 2007; Wilensky \& Reisman, 2006; Wilensky \& Resnick, 1999). Our unit uniqueness is in its use of a combination of these two different simulations, which students have to manipulate. The joint exposure to these two different perspectives is expected to increase students' ability to relate between the macro and micro levels of the complex svstem. The unit focus is the complex svstem of population growth. Data included students' pre- and posttests as well as task responses that measure their understanding of complex systems core characteristics. Although few studies have already examined the system levelrelated phenomena (Levy \& Wilensky, 2008; Wilensky \& Stroup, 2002), we are not aware of previous 
studies that focused on promoting students' system thinking by the ioint use and contrasting of the two different model-types (level perspectives) of the same system. Such approach may afford (a) the advantages of each distinct model alone, and (b) the advantages resulting from the direct contrast between different behaviors of the same system, as revealed by each perspective; that of the population macro view as a whole entity - provided by the SD-based simulation (e.g., a "straight line" representing status of equilibrium in the outcome graph) and that of this population's single agents' behaviors (e.g., fluctuations curve in the graph representing distinct agents) provided by the AB-based simulation. Such contrast may promote not only students' understanding of the interrelation between the different system levels but also their stochastic thinking and the dynamic processes involved in achieving equilibrium.

\section{Theoretical Background}

\subsection{Conceptual Knowledge of Complex Systems and The Difficulties Inherent to System Thinking}

Open systems (e.g., biology living systems, population growth), depend on constant exchanges of energy and matter with their environment, and have to maintain their state of equilibrium. Moreover, complex systems consist of components, organized in multi-scale hierarchies, with linear and nonlinear dynamic interactions among the system components (agents) within and across layers and between these components and the environment (Jacobson, Kapur \& Reimann, 2014; Wilensky \& Reisman, 2006; Wilensky \& Resnick, 1999). These feedback interactions result in the system's self-organization with observable spontaneous emergent behavior, which is different from the behavior of each component alone (Hmelo-Silver \& Pfeffer 2004; Jacobson, Kapur \& Reimann, 2014; Jacobson \& Wilensky, 2006). Therefore, understanding the emergent system behavior does not require the knowledge of all its detailed structures, and cannot be accurately predicted: "...The whole exists by means of the parts, and they are present both because of and in order to sustain the whole" (Kauffman, 1995; p. 69).

Researchers suggested that complex systems are counterintuitive in nature, (Hmelo-Silver, 2004), impede students' system thinking and require, among other abilities, the construction of a fundamental conceptual basis (Jacobson, 2001; Vachliotis et al., 2014). Among the different cognitive challenges reported are students' inability to distinguish between the different systems' levels of organization (AUTHOR, 2012; Golan Duncan \& Reiser, 2007; Hmelo, Holton, \& Kolodner, 2000); their belief that molecular processes stop at equilibrium (AUTHOR, 2012; Steiff \& Wilensky 2003); or their rejection of ideas like the self-organization, the stochastic and the decentralization behaviors of systems, due to students' "deterministic-centralized mindset" (Jacobson, 2001; Resnick \& Wilensky, 1998). Students also tend to explain systems using inadequate static mental models and sometimes misunderstand feedback mechanisms (Brehmer, 1992; 2000). Jacobson (2001) found that students as novices, reveal a reductive, linear view of complex systems as being centralized and predictable, a deficient understanding of dynamic equilibrium and a poor conceptual understanding, suggesting these deficiencies as targets for cultivation and enrichment (Jacobson, 2001; Jacobson, Kapur, So \& Lee, 2011). In light of the importance of complex systems across science and other disciplines but at the same time awareness of these systems' inherent difficulties and counterintuitive nature, it is important to study students' understanding of this construct, in the aim of designing effective ways for promoting such understanding. Therefore, the present study applied a unique learning environment, based on the use of simulations, for achieving this goal.

In the present study we chose the complex system of population growth as a simulation objective for its potential advantages to exemplify such systems' structure and behavior, thereby to promote system thinking. Population growth is a complex phenomenon involving: (a) both the micro-level of the individual organisms and the macro-level of the whole population; (b) dynamic linear and nonlinear interactions between individuals (e.g., feeding chains and webs, sexual reproduction, contagious disease transfer) and between these individuals and the abiotic environment (e.g., feeding, drinking, breathing, excreting); (c) individuals' characteristics (e.g., their reproduction rate, duration of living, feeding habits); (d) a feedback mechanism for maintaining a dynamic equilibrium of population size as related to other individuals and environmental resources (e.g., preys, reproduction and death, temperature, $\mathrm{CO}_{2}$ ); as well as (e) stochastic, decentralization, and emergent system behaviors (e.g., the uncontrolled 
increase of populations of biological species that have been transferred into new geographical areas for predating on other undesirable organisms, with no organism to feed on them). However, different factors of this complex system may be "isolated" for examination, simplifying it for learning. In addition, the topic of population growth is a sub-topic of ecology, a compulsory subject-matter in schools, and is highly relevant to present world population distribution as related to equilibrium violations, mostly the result of human activities. Increasing students' mindful awareness of the complexity of the population growth phenomenon and providing students with opportunities for problem solving in this domain, is expected to promote system thinking. System thinking in turn, has practical implications for understanding the world around us, a core science instructional goal.

\subsection{Developing Systems Thinking Using Simulations}

Several studies reported the importance of constructing a solid foundation of domain knowledge and a rich conceptual ecology by applying an explicit instruction of concepts and knowledge-integration activities for improving system thinking and its related skills (Ben-Zvi Assaraf \& Orion, 2010; Vachliotis et al., 2014; Verhoeff, Waarlo \& Boersma, 2008). Another study identified some core cognitive operations that promoted or impeded students' construction of understanding of a complex ecosystem (Eilam, 2012). Such operations were identified in the present study and termed "thinking modes" and were used as categories for exploring students' understanding.

However, most studies about the learning of complex systems were conducted using models in general and simulations in particular. Models are conceptually, mathematically or physically imperfect representations of phenomena, objects, processes or systems. They can simplify a phenomenon and make it explicit for observation and exploration, thus promote its understanding (Gilbert \& Justi, 2016). Simulations are one type of system computerized models that efficiently represent a system's dynamic operation over time and enable its variables' manipulation (Thompson \& Reinmann, 2010). Learning with simulations involves the manipulation of their represented variables in order to reveal their interrelations and the phenomenon behavior under various conditions. The latter requires the ability to translate the knowledge acquired through the simulation into knowledge regarding the target represented phenomena. Students in this study used and manipulated "ready-made" simulations in the aim of revealing the characteristics and behaviors of the phenomenon of population growth.

Simulations were found to be effective tools for promoting students' system understanding and for shifting at least to a certain extent, students' novice "clockwork ontologies" (characterized by a deterministic-centralized mindset, or failing to comprehend randomness, non linearity, emergence, or systems multiple levels of organization) toward experts "complexity ontologies" (Jacobson, 2001). For example, students with a Bachelor's degree in Chemistry were found to experience difficulties while attempting to understand chemical phenomena in the macro level by relating them to their micro level representations (Hinton \& Nakhleh 1999). Hence, simulations were used successfully to scaffold students conceptual knowledge and understanding of complex systems, gains expressed in improved problem solving abilities (Charles \& d'Apollonia, 2004; Jacobson, Kapur, So \& Lee, 2011; Resnick \& Wilensky, 1998). Jacobson, Kapur, So and Lee (2011) contend that "Developing a thorough understanding of complex systems will certainly require an extended set of activities over a longer duration" (p. 779).

Our intervention was based on the combined manipulation of two simulations that represent two different perspectives on the same system - the macro-level perspective and the micro-level one. Such manipulations may make the macro and micro levels of a phenomenon more salient, thereby promote learners' understanding of the causality that evolves from the interactions among these levels, enabling them to relate between levels and refine their conceptions of it (Nersessian, 1999; Wilensky \& Resnick, 1999). As mentioned above, learners must be aware of the fact that simulations are simplified representations of reality, and that there are different ways of representing a phenomenon, each emphasizing different qualities. Therefore, the advantages in using different representations for representing a certain phenomenon are self-evident (Boulter \& Buckley, 2000), and the choice of an appropriate form of representation is crucial for developing system thinking skills (Ossimitz, 1997). For instance, although abstract and qualitative/quantitative relationships may be represented by both equations and graphs (Giere, 1999), the latter may have an advantage in most cases, because graphs may support learners' understanding of logarithmic growth better than equations (Reed, 2010). However, the use of more than a single representational mode for learning a particular phenomenon requires 
learners' ability to map across them or to coordinate these diverse representation in order to benefit from their joint contributions in problem solving processes, shown to hinder performance unless scaffold (Steiff, Hegarty \& Deslongchamps, 2011). Relating between different simulations may also enhance learner's cognitive flexibility and promote meaningful learning (Spiro \& Jehng, 1990).

Due to learners' ability to control the simulation, researchers advocate the use of computerized dynamic simulations over static representations in facilitating an understanding of dynamic systems or for solving problems, so that the affordances of the graphics fit the goals and task requirements (Lowe, Schnotz \& Rasch, 2011). A mindful use of dynamic simulations requires the application of metacognition (Landriscina, 2013). In this study, students had to coordinate two different dynamic simulations representing the same population growth phenomenon, in order to promote this system understanding. These simulations have been chosen for responding to the need to relate the micro- and macro-system levels.

Another factor of the graphics that has to be considered is the level of concreteness of the symbols used in it. Representations of agents in AB-simulations may use iconic/concrete symbols, enabling the recognition of the agent acting in the system (e.g., representing a ship by a ship icon/picture), or may use abstract symbols (e.g., representing ship by a dot symbol). Research reported that concrete representations may assist learners initially but latter may challenge their ability to apply or transfer the gained knowledge to a new situation. By contrast, the initial use of more abstract representations may be challenging at first but eventually, the gained knowledge is easier to apply in various subject matters (Goldstone \& Son, 2005). Hence, a balanced combination of abstraction levels of simulations may promote learners' understanding of phenomena (Rogers \& Scaife, 1998).

\subsection{Agent-Based and System Dynamics-Based Simulations.}

We used two computerized simulations of the systems' operation (Parunak Savit \& Riolo, 1998): (a) is based on a System Dynamics model (SD) that expresses the temporal cause-and-effect relationships between variables, without directly representing the involved agents and its differential abstract equations are hidden from the learner due to their inherent difficulties. Such simulations enable learners' exploration of the macro-level of the complex system and present a graph representing quantitative interactions of variables within a system, stock and flow (Mandinach, 1989; Sterman, 2000). Some research findings suggest that many students have trouble understanding complex systems using SD models alone (Thompson \& Reinmann, 2010); (b) The Agent Based-simulation (AB) simulates the complex systems operations without using differential equations. Instead, the simulation focuses on the interaction between the different agents (components) that act within the system and between agents and their environment. Hence, this simulation-type enables students to explore the micro-level of the complex system and its emergent behavior (Wilensky \& Reisman 2006). The AB simulation enables a better understanding of the variability and causality of the system in the micro level, whereas the SD presents the whole picture in the macro level (Norling, 2007).

Although the separate use of the two different models was found to be efficient in analyzing a complex system, there is a paucity of empirical studies that researched the effect of combining these two simulations in teaching complex systems to school students. Studying the same system by using a combination of a top down SD and a bottom up AB simulations, may have a potential advantage in promoting the learners ability to distinguish between the micro and macro levels of a complex system, and therefore may improve their system thinking.

Therefore, our eight weeks intervention was based on a unique curriculum unit involving the combined manipulation of the $\mathrm{AB}$ and $\mathrm{SD}$ simulations representing two different perspectives on the same system - the macro-level perspective and the micro-level one, thus expected to promote students' ability to relate between these two system levels. In addition, this curriculum enriched students' complex systems conceptual ecology. The described pilot study, based on a previous study (AUTHOR, 2012) provides a foundation for developing categories for probing students' system thinking.

\subsection{The Current Study and Research Questions}

As a preliminary, exploratory investigation, this qualitative study aimed to identify the cognitive aspects involved in ninth grade students' acquisition of systems thinking while manipulating both a SD 
and an AB simulations of the same ecological system of population growth. The system included births and deaths caused by a contagious disease. We examined students' understanding of complex systems, as expressed in their system conceptual ecology, awareness of the different system levels, understanding of processes involved in reaching a dynamic equilibrium, as well as students' related thinking modes while constructing this understanding. Therefore we ask:

1. What are the changes evidenced in students' complex system conceptual ecology and complex system understanding, both along the intervention and from the pre- to the post-test?

2. What are the changes evidenced in students' expressions of different system-related thinking modes, both along the intervention and from the pre- to the posttest?

The specially designed system thinking curriculum unit presented students with some core principles of complex systems' structures and functions in an attempt to tackle some of the difficulties involved in studying this topic. The use of a combination of the two different approaches to the same complex system (SD and $\mathrm{AB}$ ) aimed at allowing students to examine and analyze the system's mechanisms and behaviors from different perspectives, while considering both micro and macro levels to form deep understanding of the system's functioning (Golan Duncan \& Reiser, 2007). The students studied the system by raising hypotheses regarding the system's behavior, then, manipulated its behavior through computerized experiments, and analyzed the results represented by self-constructed graphs. Concepts' and exercises' complexity were gradually increased along the eight-week curriculum, in line with recommendations for scaffolding practice for complex learning (Van Merrienboer, Kirschner \& Kester, 2003).

\section{Methods}

The study applied a mix method paradigm (Bryman, 2006), to enable the deep exploration of data without losing the general behavioral pattern of subjects.

\subsection{Participants}

Participants were 16 ninth graders (age 14-15; 13 boys and three girls) of middle socioeconomic background, attending junior high school in northern Israel. As part of the school requirements, they have chosen this elective one-term course of Complex Systems in the domain of science (therefore, the unbalanced gender ratio). These students studied the standard science curriculum, which approach ecology as a collection of distinct components and habitats rather than as a complex system. They and their parents gave written consent for participation in the current study according to a standard informed consent of the Israeli Ministry of Education and the university ethics committee.

\subsection{The Models Used, the Curriculum and the Procedure}

Models. The simulations used in the study for learning about the population growth system have been based on two different models. The first (SD-type model) was based on the Lotka-Voltera prey-predator differential equations (Alfonseca Carro de Lara \& Pulido, 1998). We used Excel for running the simulations because it renders the advantage of the easy comprehension of the basic mathematical operations involved (i.e., addition, subtraction and multiplication). The SD model was simulated directly by excel, which was latter used by the students to build graphs of the second AB model as well. Other Excel's advantages are that this program (differently from other pedagogical tools) is available at all schools, frequently used by school students and they are highly familiarize with it. As seen in Figure 1, learners could observe the SD's behavior by simply dragging the equation through the sheet cells. 


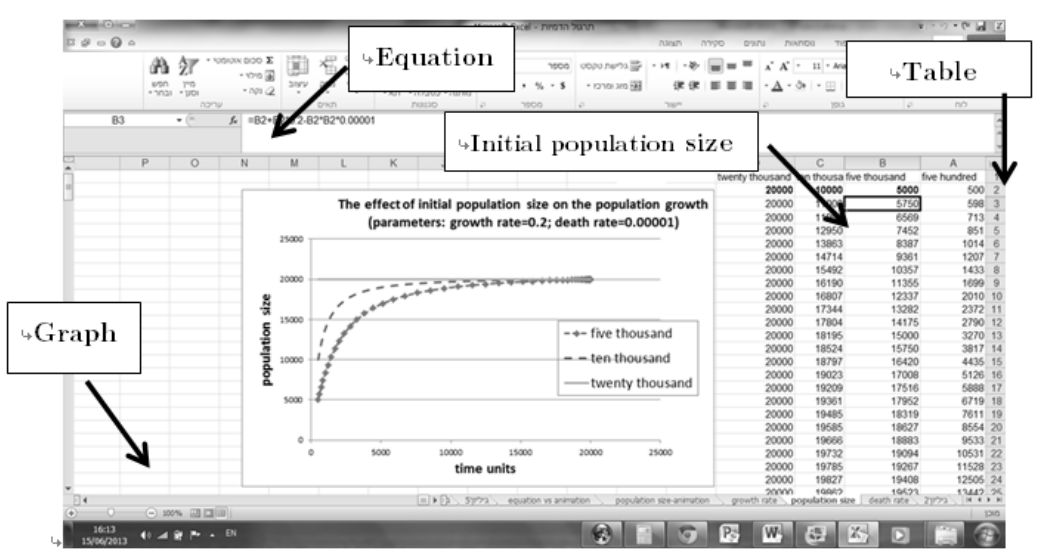

Figure 1. Excel worksheet of Sima's system dynamics model: Outcome graph for population growth after manipulating initial population size according to an equation referring to growth and death rates. Students manipulated initial population size by dragging the equation across sheet cells, and then constructed the table and graph representing the dynamic system's behavior.

The algebraic different equations were calculated by Excel as a discrete approximation of the system's differential equations. First, equations were presented and provided to the students by the teacher, indicating the system referents represented in each of the equation components (i.e., negative and positive flows; stock; birth rate -rate of the positive flow; and death rate -rate of the negative flow) (Table 1).

Table 1. Components of the equation representing a system of population growth

\begin{tabular}{c|c}
\hline Equation symbols & Symbols' meaning \\
\hline $\mathrm{Y}_{\mathrm{i}}$ & Stock in the present generation \\
\hline $\mathrm{Y}_{\mathrm{i}+1}$ & Stock in the next generation \\
\hline $\mathrm{a}$ & Growth coefficient \\
\hline $\mathrm{b}$ & Coefficient of disease spread \\
\hline$+\mathrm{a} * \mathrm{Y}_{\mathrm{i}}$ & Positive flow (births) \\
\hline$-\mathrm{b} * \mathrm{Y}_{\mathrm{i}} * \mathrm{Y}_{\mathrm{i}}$ & Negative flow (deaths) \\
\hline $\mathrm{Y}_{\mathrm{i}+1}=\mathrm{Y}_{\mathrm{i}}+\mathrm{a} * \mathrm{Y}_{\mathrm{i}}-\mathrm{b} * \mathrm{Y}_{\mathrm{i}} * \mathrm{Y}_{\mathrm{i}}$ & The model's equation \\
\hline
\end{tabular}

The second (AB-type) model was a pre-programmed model based on TCL (ActiveState, 2007), utilized previously in Netlogo and the instruction of complex systems (Jacobson \& Wilensky, 2006). Students manipulated the same parameters (i.e., birth/death rates, initial population size), and examined the resulting agents' behaviors (Figure 2) and output graphs.

Abstract symbols (circles) of different colors have been chosen for representing different agents, rather than iconic images, based on Goldstone and Sakamoto's (2003) notion that too much situational details can impair abstract understanding and transfer. They have suggested a less concrete simulations-design and in particular for low achievers. The results of students' manipulations were automatically sent from the $\mathrm{AB}$ simulation to Excel, enabling learners to construct graphs and analyze them (Figure 3). 


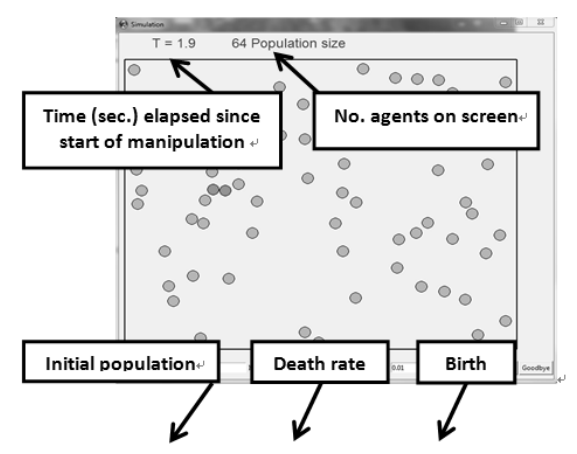

Figure 2. Screenshot of an agent-based animation representing population growth. Circles represent individuals, whose numbers may increase due to births and/or decrease due to deaths caused by infectious disease. When blue circles collide, they turn red (become infected) and disappear from the screen. Newborns begin as green and turn blue. Circle size represents disease severity, with larger numbers indicating higher death rate.

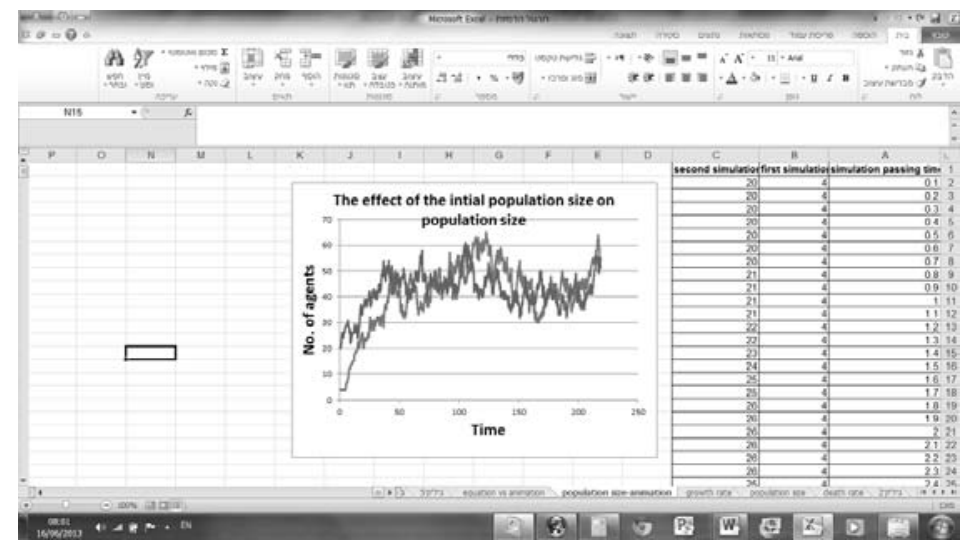

Figure 3. Shai's Excel worksheet showing population growth resulting from two agent-based animations, each with a different initial population size. Column A of the table shows elapsed time since start of simulation; Columns B and $\mathrm{C}$ show results. Shai constructed line graphs for the two populations using data from the automatically created table, and he combined the two tables into a single sheet in order to create a graph which shows the influence of the population's initial size on the system's behavior.

Curriculum. The Complex Systems course comprised of eight weekly double lessons (1.5 hours each) of computer-based study, held in the school's computer room during school hours. The course involved only in-class assignments and no homework. A pretest and an equal posttest aimed to reveal students' progress in their complex system knowledge after learning and experiencing the intervention. Their content chosen included, complex systems concepts (e.g. equilibrium, stock, flow), and system questions that required different applied thinking modes (e.g., dynamic thinking, simultaneous thinking).

The course content and timeline are presented in Table 2. Students worked individually and independently on their own computers, scaffold by a printed instructional guidebook that provided guidelines for each week's lesson; knowledge about models and simulations and practice in operating the Excel and the simulations; domain knowledge including definitions and explanations of basic concepts (e.g., stock, flow, equilibrium) and phenomena that students had to acquire (e.g., the dynamic changes of the population [stock] which is caused by the relationship between birth rate [rate of the positive flow] and death rate [rate of the negative flow]; the system reaches equilibrium when the rate of the positive flow equals the rate of the negative flow); examples of the application of these concepts in various complex systems such as, a nature reserve, or a greenhouse; and inquiry-based assignments (e.g., students were asked to investigate what is the influence of the initial size of population on the system's behavior, by manipulating at least three different initial sizes). 
Table 2. The general curriculum of the complex systems course

\begin{tabular}{|c|c|c|c|}
\hline $\begin{array}{l}\text { Lesson } \\
\text { Number }\end{array}$ & $\begin{array}{l}\text { The } \\
\text { simulation } \\
\text { used }\end{array}$ & Content & Exercises \& Manipulations \\
\hline 1 & SD - Excel & $\begin{array}{l}\text { Introduction: course guidelines, requirements } \\
\text { and assignments. Basic concepts (stock and } \\
\text { flow). SD simulation characteristics. } \\
\text { Simple SD equation of population growth } \\
\text { with births only. }\end{array}$ & $\begin{array}{l}\text { Open ended complex systems related } \\
\text { questions. } \\
\text { Exercising Excel, constructing simple } \\
\text { graphs using a basic growth equation. }\end{array}$ \\
\hline 2 & SD - Excel & $\begin{array}{l}\text { Basic concepts (stock, positive and negative } \\
\text { flows, coefficient). Dynamic changes. } \\
\text { Limitations of simulations as models. } \\
\text { Manipulating two simple simulations: a) } \\
\text { growth equation including just births (positive } \\
\text { flow) with no deaths; b) negative population } \\
\text { growth with deaths only. }\end{array}$ & $\begin{array}{l}\text { Constructing graphs from the two } \\
\text { simple simulations manipulations of } \\
\text { parameters (e.g., death/growth } \\
\text { coefficients, and initial population sizes). } \\
\text { Open ended questions regarding systems } \\
\text { behaviors based on performed } \\
\text { manipulations. }\end{array}$ \\
\hline 3 & SD - Excel & $\begin{array}{l}\text { Basic concepts of complex systems (limiting } \\
\text { factor, relationship between flows, interaction, } \\
\text { equilibrium). } \\
\text { Population dynamics in nature. Population } \\
\text { growth simulation including positive and } \\
\text { negative flows (births and deaths due to a } \\
\text { contagious disease) and the interactions which } \\
\text { influence the dynamic changes of the flows } \\
\text { and the stock. }\end{array}$ & $\begin{array}{l}\text { Manipulating parameters in the } \\
\text { population growth model (different } \\
\text { death factors, growth factors and initial } \\
\text { population sizes). } \\
\text { Open ended-related questions. }\end{array}$ \\
\hline 4 & SD - Excel & $\begin{array}{l}\text { SD and basic related concepts, processes } \\
\text { involved in achieving equilibrium. }\end{array}$ & $\begin{array}{l}\text { Exercises and manipulations of the } \\
\text { population growth simulation. Open } \\
\text { ended- related questions. }\end{array}$ \\
\hline 5 & $\begin{array}{l}\text { AB - TCL } \\
\& \text { Excel }\end{array}$ & $\begin{array}{l}\text { Basic concepts of complex systems. } \\
\text { Characteristics of the AB simulation. }\end{array}$ & $\begin{array}{l}\text { Manipulations of variables in the same } \\
\text { system of population growth using } \mathrm{AB} \\
\text { simulation. } \\
\text { Open ended-related questions. } \\
\text { Examination of system behaviors. }\end{array}$ \\
\hline 6 & $\begin{array}{l}\text { AB - TCL } \\
\& \text { Excel }\end{array}$ & $\begin{array}{l}\text { Basic concepts of complex systems. Dynamic } \\
\text { interactions between the agents and processes, } \\
\text { achieving system equilibrium. }\end{array}$ & $\begin{array}{l}\text { Exercises and manipulations of } \mathrm{AB} \\
\text { simulation. Open ended- related } \\
\text { questions. }\end{array}$ \\
\hline 7 & $\begin{array}{l}\text { AB - TCL } \\
\& \text { Excel }\end{array}$ & $\begin{array}{l}\text { Basic concepts of complex systems. } \\
\text { Characteristics and limitations of the AB } \\
\text { simulation }\end{array}$ & $\begin{array}{l}\text { Exercises and manipulations of AB } \\
\text { simulation. Open ended- related } \\
\text { questions. Emphasis on differences in } \\
\text { same system behaviors as presented by } \\
\text { the AB and SD simulations. }\end{array}$ \\
\hline 8 & $\begin{array}{l}\mathrm{AB} / \mathrm{SD}- \\
\mathrm{TCL} \& \\
\text { Excel }\end{array}$ & $\begin{array}{l}\text { A Direct comparison between } \mathrm{AB} \text { and } \mathrm{SD} \\
\text { simulations of the same population growth } \\
\text { system. }\end{array}$ & $\begin{array}{l}\text { Manipulation of the } \mathrm{AB} \text { and } \mathrm{SD} \\
\text { simulations. Comparisons of the } \\
\text { outcome behavior graphs of population } \\
\text { growth as presented in the same graph, } \\
\text { using Excel. }\end{array}$ \\
\hline
\end{tabular}

SD - System Dynamics; AB - Agent-Based; TCL - AB simulation preprogramed by TCL

Most of the guidebook tasks throughout the course required students to run and manipulate the simulations (e.g., Fig. 1) and based on the results respond to inquiry-based questions, concerning the system hypothetical behavior following changes in its variables. Some tasks required students to relate the results to specific basic complex system concepts such as flow, stock, and equilibrium, enriching 
their conceptual ecology and substantiating their understanding of these concepts. Last, students were asked to compare between the outputs of the $\mathrm{SD}$ and $\mathrm{AB}$ simulations, and explain the revealed differences. The open-ended task-type enabled a deep examination of students' understanding. Computer outputs have been saved on the computer, available for a re-examination if needed (graphs, tables, equations, worksheets) and students' responses to questions - in their personal notebooks. These served as our main data sources. Because it is likely that students' accumulated system knowledge during phase A influenced their learning during phase B, we don't compare between these two phases findings, although these pilot percentages do suggest some learning trends worthy of noting.

Instruction and learning. The science teacher clarified instructions, responded to students' questions by explanations, and referred students back to the data on their computer screens, their guidebooks, or to their notebooks. In the first lesson, she has provided a detailed instruction about the spreadsheet program (Microsoft Excel) to be used for manipulating the two types of simulations. As described above, Excel is relatively easy to use as compared with other system dynamics simulations and is familiar to most junior high school students. The curriculum composed two main phases, the SD phase and the AB phase.

The SD phase (Table 2): This phase was chosen to be enacted during the course first 4 weeks, because it requires higher abstraction abilities, assuming students' motivation is higher in the beginning of the chosen course than at its end (end of year). In addition, their familiarity with Excel made it easier to start manipulations. Students encountered increasing system complexity levels over time (i.e., logarithmic growth comprising of births alone, then of deaths from a disease only, and finally, a simulation combining both). Students' simulations with the SD models were performed directly by Excel, which was later used by the students to build graphs of the AB simulations as well (Figure 1).

Students used the given equation and performed their computerized manipulations on two of its parameters: birth/death rates and initial population size (initial stock). Students dragged the equation through the Excel sheet cells to create tables and graphs, then analyzed their graphs to conclude about the system's behavior as related to the change in its parameters. Prior to performing the manipulation, students raised research questions regarding the possible influence of various manipulations on the system behavior (e.g., "how would the system behave if the initial population size would increase?") and hypothesized about it. After manipulating these parameter three times at least, reassigning three different values (e.g., three different initial population sizes), they constructed graphs and analyzed their results, describing and discussing these data using the acquired complex system concepts (e.g., components, flows, relations between the flows, which influenced the stock, or the equilibrium achieved as related to the flow).

The AB Phase (Table 2): In this phase (course last $5^{\text {th }}-8^{\text {th }}$ weeks) students were already familiar with most of the relevant contents and basic concepts, acquired through explanations, the guidebook and their own experiences with the various tasks. Hence, most of part B time was devoted to the learning through the manipulation of the AB simulation. Learners used a pre-programmed model (Jacobson \& Wilensky, 2006). Students manipulated the same parameters (i.e., birth/death rates, initial population size), and examined the resulting agents' behaviors (Figure 2) and output graphs.

Lesson seven and eight were devoted mostly for comparisons between the behaviors of the same system as presented by the two simulations. Hence, the time devoted to each of these models was similar.

Once students learned about the same complex system using both simulation perspectives, they were asked to compare the system behavior as modeled by these two perspectives; the macro level of the system, represented by the SD equations, and its micro level, represented by the AB simulation. Figure 4 presents an example of such a comparison targeting the concept of equilibrium. Comparisons required the inserting of the same birth/death rates and initial population sizes into both simulations. 


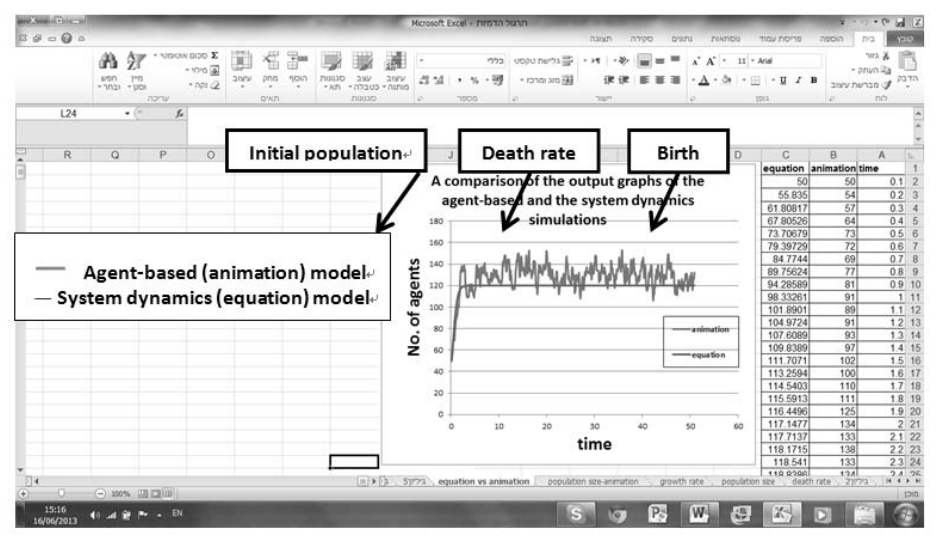

Figure 4. Aryeh's Excel worksheet exhibiting his results from population growth simulations using both models: agent-based and system dynamics. He inserted the correct equation for the animation in the second row of the table and dragged it through the sheet cells, constructing the table and the line graph presenting both models.

\subsection{Data Collection}

Qualitative data were collected throughout the eight-week course from the students' task-and testrelated performance. This included students' written responses in their notebooks to the open ended questions and their explanations for their computerized outputs, as well as their pre- and posttests responses. Students' short classroom sporadic comments, directed at classmates or the teacher, were collected by audiotapes.

\subsection{Data Analysis}

All audiotaped classroom students' comments were transcribed. Together with all other students' written verbal and graphic data - the task and test-related performance of the 16 students over the course, were qualitatively analyzed for their content (Maykut \& Morehouse 1994). We aimed to grasp the broad picture of how the whole group learned with the two models promote students' system thinking. At the same time, we also focused on specific students' responses to different tasks and activities. These students' expressions shed light on different aspects of understanding the system. Because the audiotapes transcripts added mostly students' oral comments while performing the tasks, there was no need to analyze them separately from other written responses. We also used the audio as evidence for the lessons' progression as transpired along the course work. As frequently is the case in an ecologically valid study, not all students responded to all tasks. An in-depth examination of the outcomes of the curriculum unit implementation in this specific context, aimed to reveal its feasibility.

We applied two predetermined core categories related to our research questions: (I) conceptual knowledge (systems' components, system' basic concepts and dynamic equilibrium in particular); and (II) expressions of different thinking modes that promote versus hinder system thinking (e.g., stochastic thinking, multidimensional thinking, simultaneity), based on the $1^{\text {st }}$ author's prior findings for a similar domain, and used successfully for evaluating students' system thinking (Eilam, 2012). These categories have been applied in the pre- and post-test analysis as well. Each of the two category has several values as described below.

The unit of analysis constituted a single to several sentences expressing one single topic, that could be classified into one of the aforementioned categories and their values. Two independent judges, experts in complex systems, categorized units of a random selection of pages constituting $21 \%$ of the entire written data set (including written and audio students' responses). Disagreements were discussed and category definitions refined. This process yielded a final inter-judge reliability of $84.11 \%$ (agreement on 503/598 units). 


\subsection{Category I: Knowledge of Complex Systems' Basic Components and Concepts.}

We analyzed students' ability to identify main interrelated components and processes of the population growth complex system and assessed their level of understanding (i.e., stock, flow, relations between flows, coefficient, limiting factor, interactions, and equilibrium). According to SD perspective, the main two basic concepts essential for understanding complex systems, are stock and flow (Ossimitz, 1997). Stock is defined as an accumulation of any kind of entity (e.g., water in a bathtub, food, population). Flow is a process that changes the level of the stock. For example, when the water in a bathtub constitutes the stock of the system, the flows that may change this stock may be the strength of the water flow into the tub (positive flow - increases the level of the stock) or of the drainage (negative flow - decreases the level of the stock). Dynamic changes of stocks and flows may be controlled over time to achieve equilibrium (Forrester, 1992). In the present study, the system of population growth consists of population size (stock) which was changed according to deaths (negative flow) caused by a contagious disease and births (positive flows). The dynamic changes of the population size were caused by the relations between the positive and negative flows, which were influenced by their respective rates. These rates include the death rate - the limiting factor, and the growth rate - the growth coefficient. Interactions over time among individuals in the system population spread the lethal disease on encounters. A dynamic equilibrium may be achieved when growth rate equals death rate. Differently from this $\mathrm{SD}$ perspective, the $\mathrm{AB}$ perspective emphasizes the concepts of interactions and equilibrium (Wilensky \& Reisman, 2006).

Scoring category I: With regard to students' understanding of a concept: an expression that revealed a complete misunderstanding ("there are no deaths and no births in an equilibrium state," revealing a deficient awareness of the dynamic processes) was scored 1; for a partial understanding was scored 2 (e.g., exhibiting inaccuracies or some correct and some incorrect response parts, e.g., "in equilibrium, the population size stayed the same" without indication of understanding the process that brings about equilibrium); and for a full understanding was scored 3 (e.g., notebook comment: "In an equilibrium state, birth rate is identical to death rate, which causes population size to stay steady and balanced"; computer-saved equation showing that in the equilibrium state, current stock equals previous stock at each point in time (i.e., " $Y_{i+1}=Y_{i}$ ").

\subsection{Category II: Expressions of Various Thinking Modes.}

We define "thinking modes" as the kind of cognitive higher order operations that students have to apply in order to construct understanding of the complex system and promote system thinking, whereas their deficiency impedes system thinking. The high-order thinking modes that promote system thinking, include (a) dynamic thinking - ability to perceive events as they occur over time and grasp the evolving changes in them (e.g., "It takes time until the individuals meet each other. At the same time more multiply and fewer meet and die."); (b) multidimensional thinking - ability to consider linear and nonlinear occurrences and phenomena, reversibility and divergence of processes (e.g., "When a limiting factor [predator population] is lacking, the deer population will grow and grow until it becomes impossible to regulate it and they [the deer] will finish all sources of food."); (c) parallel or simultaneous thinking - ability to understand that many events, interactions, and phenomena in a complex system occur simultaneously rather than sequentially, even if not related (e.g., "There are three possibilities: If the negative flow is bigger than the positive flow the number of deer will decrease; If the positive flow is bigger than the negative flow the number of deer will increase; and If the negative flow is equal to the positive flow the number of deer will not change."); and (d) stochastic thinking - ability to understand statistical issues such as average (e. g., "...the fluctuation in the population size around the same average point.").

Low-order thinking modes that may hinder system thinking, include: (a) linear thinking -or onedimensional thinking- disregarding and inability to perceive any divergence or reversibility of occurrences, processes or interactions, perceiving all interactions as one causing the other in a linear fashion (e.g., ignoring the indirect influence of lack of predators on the prey population); (b) concrete thinking- perception of the implicit and the abstract pose challenges (e.g., "I've never learned with $\mathrm{Y}_{\mathrm{i...}^{.}}$); and (c) static thinking - perceiving dynamic continuous phenomena as static one with no changes over time (e.g., "So the number of deer will neither increase nor decrease"). 
Scoring of category II: Each unit of analysis which expressed one of the above thinking modes was classified to the high-order thinking modes' group or to the low-order thinking modes' group. Then, in the analysis, the total number of high order and low order modes was calculated in percentage.

Students' pre- and posttest was analyzed to reveal the effect of the curriculum unit on students' knowledge and understanding of the complex system. Averages of the two core categories were examined within subject numbers by a two-tailed, type one t-test $(\mathrm{df}=\mathrm{n}-1)$ and compared. In order to gain a general view of students' diverse task performance, we scored all students' knowledge and understanding in the two categories, calculating percentages of concepts and processes-related correct statements and of their modes of thinking.

\section{$4 \quad$ Results}

Findings are presented separately for each of the two core categories - conceptual knowledge, and thinking modes, based on evidences from both the pre-posttest and students' course performance. The verbal expressions presented from the tests relate to the pool questions (see Appendix A), a case not studied during the course. It should be noted again that generally, students' easier and faster dealing with the AB simulation, following their manipulation of the SD-based simulation, may be explained by their growing experience with simulations. We have no evidence for these impressions being related to the simulation type.

\subsection{Category I: Students' Conceptual Knowledge}

The findings presented in Figure 5a, suggest that overall, learners' conceptual knowledge improved from the pre to the post-test. In spite of the relatively high variation among the students (SD > 50\% of the average), the two-tailed, type one t-test results $(\mathrm{df}=15)$, comparing the average scoring of all the concepts together, showed a significant improvement in the number of correct answers from the pre to the posttest $[\mathrm{M}=1.7(\mathrm{SD}=1.2)$ to $\mathrm{M}=2.7(\mathrm{SD}=1.4)$ respectively, $\mathrm{p}=0.0007]$. Comparisons between preand post- tests for each concept showed significant differences $(p \leqslant 0.05)$ for the concepts: stock $(\mathrm{p}=0.0003)$, flow $(\mathrm{p}=0.0005)$, relationships between flows $(\mathrm{p}=0.004)$, interaction $(\mathrm{p}=0.002)$, and equilibrium ( $\mathrm{p}=0.01)$, (Fig. 5a).

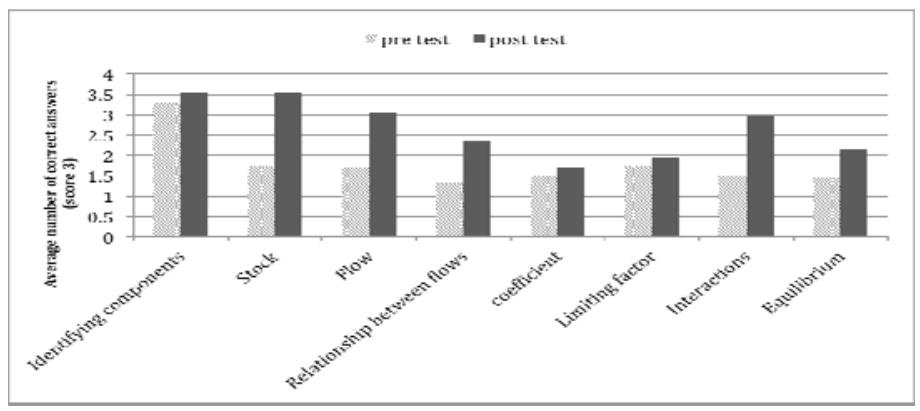

Figure 5a. Category I: Students' conceptual knowledge (identification of system components, understanding of system-related concepts), as exhibited in the pre and posttests.

The variation among the students can be demonstrated for example regarding the concept of equilibrium. Although most students improved their understanding of this concept and the processes involved in achieving equilibrium, it remained a challenge for few others all through the course. For example, in the Appendix we present the problem of the pools administered to students in the pre- and post-tests. We also explain there the expected correct answers to the presented problems. In the pre-test Gaia could not answer question b and could not say which of the two pools is more stable if in both pools an increase in the positive flow of water would occur. In the post-test she erroneously answered that "pool B is more stable because it is known that an increase in the water surface area in a pool, results in increased evaporation. Therefore, pool B, which has a smaller surface area stays more stable." 
Other students did exhibit improvement in their conceptual understanding of equilibration processes. Ron, who like Gaia didn't answer the aforementioned pools question in the pre-test, expressed an understanding of the relationship between the flows in his post-test: "in order to calculate the water level one must relate to the amount of water according to the surface area as well as to the evaporation rate... Pool A is more stable than pool B, because once you increase the flow of water, its surface area will also increase as well as the evaporation rate." Ron did show an understanding of the relationships between the flows and their influence on achieving equilibrium but didn't explain in depth the processes involved in those two systems and didn't compare pool A to pool B.

Maya did compare the two pools in her post-test and did show a good understanding of equilibrium by writing correctly that "Pool A is more stable than pool B: The surface area of the water is larger in pool A and so is the evaporation rate, so a steady flow of water into the pool stabilizes the water level. In pool B, the surface area of the water is smaller and so is the evaporation rate, therefore a flow of water into the pool will cause an overflow of the water outside the pool." These examples of different students' responses to the pool project are not presented for the purpose of comparison. They are presented to demonstrate the differences in students' understanding of equilibrium. Such variability characterizes any heterogeneous classroom, and results from different processing and construction of same curriculum acquired knowledge due to academic (e.g., prior knowledge, abilities) and personal (e.g., interest, motivation) differences in students' characteristics. However, it raises our awareness of the type of difficulties some students encounter, which may be contribute to the development of an improved curriculum version.

Along the course timeline, students' conceptual knowledge, as expressed in their understanding of basic concepts and ability to identify system components, increased notably. Most system components and concepts have been acquired during the first phase of the curriculum, targeted by relevant assignments (see Table 1). This knowledge provided a foundation for continued development and refinement in the second phase, while manipulating the $\mathrm{AB}$ simulation, which granted this knowledge new and additional meaning from a different perspective, resulting in this conceptual knowledge internalization over time. All together, this process supported the development of a rich conceptual ecology. Overall, findings suggest that learners' engagement with the simulations and their use of concepts in their task responses improved from the first to the second phase.

We next present students' conceptual knowledge as manifested in their tasks performance in the two phases.

The case of equilibrium. In-depth examination of students' understanding of the complex concept of equilibrium suggests a development from static to dynamic perceptions along the course. Initially, while manipulating the SD simulation, most students exhibited a basic understanding of the static characteristics of equilibrium: "In equilibrium the population size stays steady" or "In equilibrium the population size doesn't change." While adding the manipulations of the AB simulation in the second phase to their previous experiences regarding the same system, most students recognized the dynamic zone of equilibrium in their constructed graphs. Students described the system state of equilibrium as: "a zone in which there are fluctuations around a steady value." Furthermore, after comparing both simulations outputs of the same system (Week seven-eight, see Figure 4), students exhibited an improved understanding of both the phenomenon of dynamic equilibrium and the different ways these two simulations depict this phenomenon. Among other tasks, students were asked to consider the duration needed for reaching equilibrium in cases of different initial population sizes.

David indicated: "The equation [agent-based simulation, as expressed by the graph] reaches a point of equilibrium and then stops [stays steady]. The agents [based simulation, as expressed in the graph] describes in addition, the fluctuation in the population size around the same average point [the value of equilibrium expressed by the equation]." Typifying the trends shown by the study participants, David demonstrated improvements in his conceptual knowledge after experiencing the combined simulation perspectives. While focusing on the system dynamics models, David perceived the system's equilibrium as static, with a halt in population growth following its reaching a certain limit: "An initially larger [population] will be balanced faster. The population grows up to a limit, which relates to the positive and negative coefficients, and then stops [growing]. The closer the population is to this limit, the less time it will require to achieve it [equilibrium]." David's initial static perception of equilibrium probably stemmed from the SD graphs' presentation of population growth as a straight curve that levels off (see Figure 1). Later on, after observing the AB simulation graph as well, David described the process of 
reaching equilibrium as follows: "In theory, a very high limiting factor (the coefficient of the mortality rate due to the contagious disease) in a small population may prevent the population from reaching stability and may cause its extinction." Following his attempts to reach equilibrium by manipulating the initial population size variable (AB simulation, second Phase, week 6), he was able to accurately define equilibrium as a dynamic "range of numbers," rather than as static: "In all three trials, the population ranged around the same numbers. Obviously when the initial population is smaller, it will take longer to achieve the right range.... The average was in the same range.... There are fluctuations, but most of the graph is in the 40-60 range. The system stabilizes around 45."

As mentioned above, other students too defined equilibrium initially as a static situation while studying population growth in the first Phase, while using the SD equations only. As related to the case of disease infection, Maya for example, defined equilibrium as: "A situation that will stay steady." Later on, she has demonstrated an improved understanding of the process of reaching equilibrium, saying that: "The population will reach equilibrium when reproduction is equivalent to mortality," referring to the influence on the system stock (the population) of the relationship between the flows of reproduction and mortality (see description of SD equation in section 3.2 and Fig. 1). After manipulating different disease coefficients, Maya was accurate while stating that: "When the limiting factor [disease coefficient] increases, the value of equilibrium decreases." Relating to equilibrium, her correct hypothesis before manipulating the initial size of the population was that: "As the initial population size increases, equilibrium will be reached sooner, but this initial population size will not affect the specific point of equilibrium reached, which will stay the same." However, later on in the course, during phase B, while manipulating the $\mathrm{AB}$ simulation and observing the agents' circle sizes (see AB simulation section 3.2, Fig. 2), her understanding of the dynamic character of equilibrium deepened as well as her consideration of the interactions within the complex system. She described the two simultaneous events, saying: "It takes time until the individuals [represented by the circles] meet each other. At the same time more [individuals] multiply and fewer meet [become infectious] and die." The AB simulation probably enhanced her understanding of the influence of the circle size (severity of disease contagion) on death, where circles represented individuals in the population: "...Also the size of the circle has an influence. Larger circles die sooner due to increased contagiousness. It is not that they multiply less, they just die more."

Increased understanding of components and interactions while using the $\mathrm{AB}$ simulation may have been afforded by the concreteness of this representation. This simulation allowed learners to see color changes depicting both deaths, due to lethal infection and births of agents, due to reproduction. Moving circles that were close to each other, touching, and moving apart, may have helped learners tangibly visualize the notion of individual agents operating within the system. The $\mathrm{AB}$ simulation also may have demonstrated the meaning of randomness, represented by the dynamic fluctuations of population size over time by parallel processes of death and birth. The fact that the SD simulation is more abstract than the $\mathrm{AB}$ one, was expressed in students' difficulties in understanding the abstraction of the equation. However, in spite of this abstraction, all of the students $(n=16)$ did succeed in constructing suitable graphs for the population growth system, even when using the more abstract equations in the SD simulation as compared with the $\mathrm{AB}$ simulation. For example, in one particular exercise (Week 4, first Phase), students were asked to calculate the population size in a system that is in a state of equilibrium, by using the equation alone, before running it in Excel. In this task, the vast majority of students $(n=$ $15 ; 94 \%$ ) expressed difficulties in moving from a verbal expression of equilibrium to an abstract symbolic expression of the equation, showing that the stock $\left(Y_{i}\right)$ stays steady over time: $Y_{i+1}=Y_{i}$. Some of the students could not succeed at all in expressing equilibrium as an equation, adhering to the concrete number they had obtained in their previous computerized manipulation of the population size at equilibrium, such as "1000." Even after receiving the accurate equation for equilibrium, some of the students could not succeed in solving it. This deficient performance may have evolved in part from the use of unfamiliar symbols in the equation. For example, Ray indicated "I've never learned with $\mathrm{Y}_{\mathrm{i}}$," and changed the $\mathrm{Y}_{\mathrm{i}}$ symbol to $\mathrm{X}$, which was familiar to her from mathematics.

\subsection{Category II: Thinking Modes Expressed in the Course of Learning}

Overall, learners' promoting system thinking modes (e.g., dynamic or multidirectional thinking), improved from pre to post-test (see Figure 5b). 


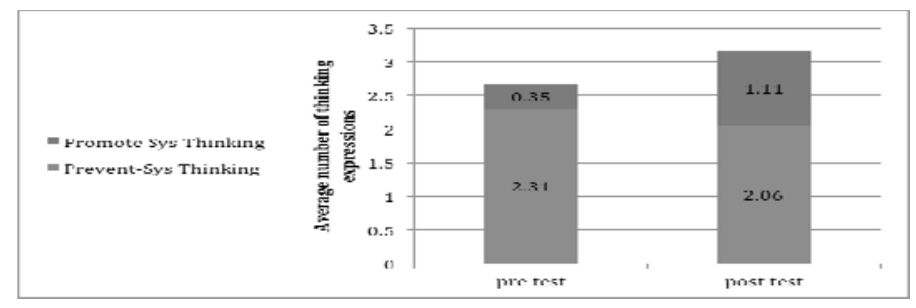

Figure 5b. Category II: Thinking modes as expressed by the students in the pre and post- tests.

Compared with the pre-test, significantly more promoting systems thinking modes were expressed in the post-test [pretest $\mathrm{M}=0.4(\mathrm{SD}=1.8)$ and posttest $\mathrm{M}=1.1(\mathrm{SD}=1.6), \mathrm{p}=0.01$ ], although the number of inhibiting modes (e.g., linear or static thinking) was not significantly reduced (pretest $\mathrm{M}=2.3(\mathrm{SD}=1.8)$ and posttest $\mathrm{M}=2.1(\mathrm{SD}=1.5), \mathrm{p}=0.4]$. For example, in his pre-test Jack expressed a concrete mode of thinking by writing that "you can define the level of the water in the pool by a ruler" and that "Pool B is more stable than A because the way it closes its water and keeps them inside the pool." This concrete and somewhat static mode of thinking was also evidenced in Jack's post-test response. Although he identified the components of the system, his answer was erroneous: "Pool B is stable because its surface area is smaller and so is the evaporation rate and pool A is unstable because its surface area is bigger and so is the evaporation rate."

By contrast, David expressed a dynamic thinking mode in his post-test by answering that "Only pool A is stable. If we increase the flow in pool A, the contact of the surface area of the water with the air increases too, and the evaporation increases and can achieve the rate of flow and balance the equation. Differently, increasing the flow in pool B will decrease its surface area and the flow of water will be greater [than the evaporation]."

Students' general improvement was also evidenced along the course. In Phase A of the program, 31\% of students' verbal expressions (16/52 units of analysis) were promoting modes, whereas $69 \%(36 / 52)$ were the hindering kind. In the second Phase, following students' experiences with the additional AB simulation and the comparisons between the simulations, the percentage of promoting modes increased to about $87 \%$ (20/23 units of analysis), whereas the inhibiting modes decreased to $13 \%(3 / 23)$.

We next present students' various thinking modes as manifested while completing tasks in the two different phases. In the beginning of the first lesson students were introduced to a real event followed by a question:

In 1907, deer hunting was prohibited at a U.S. nature resort while boosting the hunting of lions and other deer predators. As a result, the size of the deer population increased tenfold, from 5,000 in 1907 to 50,000 in 1922, while their predators became almost extinct. Then, after the winters of 1924-25, $60 \%$ of the deer population died. Which factors could have influenced the drastic decrease in deer population after 1922 ?

At this baseline stage, before using the simulations, about $86 \%$ of the students expressed linear and unidirectional thinking mode while reasoning about the decline in deer population. For example: "The deep cold during the winter could hurt the deer and kill them, or fire in the woods, which destroyed their habitats" (Ray) or "Lack of food and water, natural disasters like fires, earthquakes, and diseases" (Maya). Such low-order thinking disregarded the system as a whole, especially the implicit processes by which the deer predators' extinction eventually caused the deer population to dwindle, because the unbridled deer population exterminated their own limited food sources. Only David exhibited a multidirectional mode of thinking at this stage:

It is caused by the increase in the deer population. Due to the massive hunting of their predator population, there was no balance between the positive and negative flow. Due to the growth of the deer population there is a lack of food. This is what can happen in a system that has population growth without a limiting factor. When a limiting factor [predator population] is lacking, the deer population will grow and grow until it becomes impossible to regulate it and they [the deer] will finish all sources of food. 
In the end of the first lesson, students were presented with their first SD simulations of a simple system, comprising a growth equation, with birth only, and were asked: "What would happen over time to a system that grows without any mortality if it has a negative flow as well as a positive flow?" Most of the students who answered this question $(n=4 / 5 ; 80 \%)$ continued to reveal hindering thinking modes. Ori provided an example of a factor that could cause negative flow: "If the food that deer eat runs out because of their growth, they will start dying;" however, this response suggested linear thinking that ignored the two simultaneous processes of growth and death in the population. Such linear, unidirectional thinking may impede understanding of dynamic interactions that leads to equilibrium when negative flow equals positive flow. Shalom also demonstrated a misunderstanding in writing: "So the number of deer will neither increase nor decrease" describing the system as lacking any reproduction or death, hence revealing a hindering static mode of thinking. In contrast, Gaia's response to the simple growth equation reflected an ability to analyze the simultaneously occurring dynamic processes in the system (reproduction and death), as well as to predict several system behaviors as a result of different conditions and interactions within it, thus expressing a high-order simultaneous promoting thinking mode:

There are three possibilities: (1) If the negative flow is bigger than the positive flow the number of deer will decrease; (2) If the positive flow is bigger than the negative flow the number of deer will increase; and (3) If the negative flow is equal to the positive flow the number of deer will not change.

Moving from the first to the second Phase and adding the manipulations of the AB simulation, students showed increased incidences of promoting thinking modes by the development of a stochastic dynamic thinking. During lessons 7-8, students compared the depictions of the same phenomenon by the two simulations (SD and $\mathrm{AB}$ ), by explicitly navigating between the system macro and micro levels, which probably enhanced their understanding. For example, when comparing a system's behavior as represented by an equation to its behavior as represented by the AB perspective, David expressed stochastic thinking as well as thinking about the dynamic changes occurring in the system over time:

The simple equation in Excel describes the average and the growth, while the agent-based simulation imitates the movement of individuals in the system and therefore, does not [describe] the average. The agent-based model contains a randomness factor, meaning that the situation is not static and therefore, is closer to reality. The equation describes the average of the occurring events. In the agent-based simulation we also see the deviations from the average.

David correctly distinguished between the average value, which was reflected by the macro level represented by the SD equation, and the deviation from this average, represented by the AB simulation - the micro level. Ron compared these random fluctuations and dynamic events as represented by the two simulation outcome graphs:

Randomness exists, reaching equilibrium through fluctuations of ups and downs. It will continue to be waves and waves, reaching stability somewhat, plus or minus a middle point between the peak and the bottom [of the fluctuations], which cyclically returns to itself... The closed graph [based on the equation] is steady; its death coefficient is well defined and is not a sort of probability as with the circles in the agent-based simulation. This latter simulation graph is in fact a model of probability in which the point of equilibrium is not defined. It is not one number, it is some average, some range. In the first graph [based on the equation], it is a single, fixed, and a very much defined number.

Ron expressed a somewhat limited understanding of the stochastic meaning of an average, which was described according to him only by the SD of the equation. However, when asked about the graph of the equation later on, he explained: "The curved line is sort of an average of the AB simulation." Thus, it appears that Ron's comparison between the outputs of the two simulations representing the same phenomenon, probably sharpened his dynamic and stochastic understanding. This may suggest that exposure to the two complementary models resulted in the $\mathrm{AB}$ simulation emphasizing randomness and fluctuations occurring over time in the micro level, by visually presenting the "Ups and downs, and waves" in Ron's language, whereas the general equation, expressed in a single line, probably emphasized the general trend and the average which is reflected by the macro level of the system.

In the second Phase, while manipulating the $\mathrm{AB}$ simulation of population growth, Maya, who previously expressed linear thinking, was able to express a larger number of higher order thinking modes. For example, when asked about equilibrium in a system, she defined it as "returning to itself on a regular basis" and elaborated about the individual agents in the simulation: "The fluctuations are like they happen in reality. It takes time until the individuals meet each other [and then die due to infection] 
or until they multiply, and it all happens in fluctuations," indicating her awareness of dynamic changes in the micro level of the system represented by the agent based model. She was also able to distinguish between two different parallel and simultaneous processes: "The size of the circle doesn't influence the population's growth rate; if the circles are larger it's not that they multiply less, they just die more."

In contrast to Maya, Ray continued to express linear and concrete thinking during Phase B in spite of the additional $\mathrm{AB}$ perspective: "Suppose that $1 / 3$ of the population catches the disease, so if there are 3 items, just one will catch the disease and if there are 12 items so 4 will catch the disease." Although she understood correctly that population growth will increase contagiousness, she based her description on concrete numbers and incorrectly perceived the disease's spread as a linear process. This deficient understanding suggests she misunderstood the previous model of the growth equation, which represented exponential growth $\left(\mathrm{Y}_{\mathrm{i}+1}=\mathrm{Y}_{\mathrm{i}}+\mathrm{a} * \mathrm{Y}_{\mathrm{i}}-\mathrm{b} * \mathrm{Y}_{\mathrm{i}} * \mathrm{Y}_{\mathrm{i}}\right)$.

These are some examples of students' progression in thinking from static toward a dynamic thinking mode, from linear toward nonlinear and simultaneous thinking, and from perceiving individual agents toward the ability to understand the meaning of an average (i.e., stochastic thinking), using words like fluctuations. Many of the students exhibited a static view of the system behavior, disregarding changes over time and no one exhibited an awareness of stochastic phenomenon/behavior in the beginning of the course. Thus, the explicit comparison between the two different graphs (outcome of the two different models) at the end of the course probably initiated a dynamic and stochastic thinking modes, promoting system thinking in most of the students. However, as mentioned before, and exemplify here, few students in the classroom exhibited linear and concrete thinking modes till the end of the course.

\section{Discussion}

This study presents a novel way of promoting system thinking in the context of school science. It involved an emphasis on enriching students' conceptual ecology and individual manipulations of a dual simulation-based curriculum focusing on the same complex system, which thus promoted students' ability to relate between this system macro and micro levels. Using a set of categories based on system characteristics, ninth graders' system thinking was examined before, during and after learning this onesemester Complex Systems curriculum unit that scaffold their learning processes. Data sources comprised of students' pre and post-test responses as well as their task performance data. The study revealed most students significantly improved their understanding of complex systems along this intervention.

Students manipulated variables in the SD simulation examining the growth system deductively (topdown - focusing on the system macro level) (Forrester, 1968), and the AB simulation examining the same system inductively (bottom-up - focusing on the system micro level) (Wilensky \& Resnick, 1999). They compared the two simulations outputs using self-constructed graphs on Excel worksheets. We developed these two-simulations curriculum unit based on reported findings regarding these simulations' separate effects on system thinking acquisition, and suggestions regarding this approach (Levy \& Wilensky, 2008; Wilensky \& Stroup, 2002). However, we found no precedent for our combination of two different perspectives on the same complex system, which enabled students' shifts between the system levels. Thus, the current study's findings comprise a preliminary exploration of a potentially important dual conceptual approach to assist educators in tackling students' well-documented difficulties in system thinking and their ability to move between the system's micro and macro levels. Note, that these preliminary results pertain to the curriculum unit that begun with the manipulation of the SD simulation and continued with experiences built on the manipulations of the $\mathrm{AB}$ simulation, developed based on some assumptions. It is fairly possible that a unit beginning with manipulation of the $A B$ simulation would yield different results. Next we discuss out findings in the order they were presented.

Our findings support researchers' notions of the topic "learnability" at school (Jacobson \& Wilensky, 2006) and shed some light on the processes involved in complex systems instruction and learning as they transpire in this authentic context. Generally, students improved their understanding of the population growth system, and expressions of promoting thinking modes (not the hindering ones) increased along the course. Awareness of such thinking modes may support teachers and curriculum developers in their efforts to target effective specific enhancers and barriers to system thinking acquisition. 


\subsection{Students' Conceptual Knowledge}

Mostly, the curriculum enhanced students' conceptual knowledge from the pre to the post-test. However, a closer look at individual students along the course revealed a great diversity, with some students exhibiting difficulties regarding those concepts that involved simultaneous and dynamic thinking in spite of learning the curriculum. A holistic understanding of the system's behavior requires deep comprehension of many system aspects (e.g., concepts, components and their interrelationships, mindfulness of different coefficients; equilibrium processes), which are difficult to acquire in a short intervention (Jacobson, Kapur \& Reimann 2014; Kauffmen, 1995; Wilensky \& Resnick, 1999).

Students' initial challenge to understand the basic concept of equilibrium may have evolved from their difficulties in distinguishing between the system's macro and micro levels (Levy \& Wilensky, 2008), from the difficulties experienced while attempting to distinguish between the system's structure and behavior (Hmelo-Siver \& Pfeffer, 2004) as also found in previous studies (Eilam, 2012; Ben-Zvi Assaraf \& Orion, 2005; Hinton \& Nakhleh, 1999; Hmelo-Silver et al., 2000; Moxnes, 2000), or from their attempt to use the equation for explaining equilibrium $\left(\mathrm{Y}_{\mathrm{i}+1}=\mathrm{Y}_{\mathrm{i}}\right.$ ) (Goldstone 2006), with its unfamiliar symbols, like "Yi.".

Students' initial definitions of equilibrium revealed a static mental model of the phenomenon, probably stemming from the equation-based graphs that leveled off horizontally (Figure 1). Indeed, dynamic simulations advantages over static representations for representing dynamic processes in certain conditions, were reported by previous studies (Lowe et al., 2004). A dynamic perception of equilibrium as fluctuating within a range was generally achieved by most students only after experiencing the $\mathrm{AB}$ graphs' oscillating lines (Figure 3).

The explicit comparison between the two computer output graphs refined students' perception of the dynamic system behavior and deepened their conceptual understanding of the interactions within the system. These simulations provided complementary information from both the macro and micro perspectives (Norling, 2007). Learners' dynamic linkage ("dynalinking") between the two representations of the same system (see Rogers \& Scaife, 1998), enabled these representations' clear distinction, and the visualization of the macro level as emerging from the micro-level interactions occurring among the system components.

\section{$5.2 \quad$ Thinking Modes}

Current sample's initial tendency toward static thinking resembled findings from previous studies (e.g., Ben-Zvi Assaraf \& Orion, 2005; Moxnes, 2000; Ossimitz, 1997), probably stemming from students' customary exposure to static pictures of the world in the course of their formal and informal education (Forrester, 1992). The two perspectives and simulation output comparisons enhanced learners' system thinking. For example, the visual presentation of several parallel processes in the AB simulation probably enhanced learners' ability to think about simultaneous occurrences, and construct improved mental models.

In addition, most people are unfamiliar with probability models, and their intuitive judgment is usually biased and differs from the statistical model (Garfield \& Ben-Zvi, 2008). Such mistakes effect individuals' explanations and understanding of the phenomenon at hand. Our findings suggest that the combined simulation presentation and students' active construction and comparison of the graphs (Figure 4), promoted many students' stochastically thinking with respect to randomness and their understanding of the meaning of variability, supporting prior research (Garfield \& Ben-Zvi, 2008). In particular, the $\mathrm{AB}$ simulation had strengthened their understanding of randomness by visually simulating the dynamic fluctuations, in contrast to the equation model that presented the overall trend of population growth.

\section{$6 \quad$ Summary and Conclusions}

Our curriculum unit was found to promote, at least to a certain extent, most students' understanding of a complex system, in two main areas: their conceptual understanding, and some of their system thinking skills. The main contribution of this study is therefore, showing a way for developing a mode of learning that combines two different models, which promote students' shift between the system macro and micro- 
levels, thereby deepening students' understanding of the system and the complex process of achieving equilibrium. It is an initial step in the uncovering of different cognitive aspects during learners' active involvement with this curriculum. To the best of our knowledge, the teaching of complex systems by explicitly integrating and contrasting two different approaches is innovative, and as such, our findings should be considered preliminary and do require replication and validation.

Several key learning environmental elements that likely contributed to the development of students' reported abilities are: (a) the structured self-regulated inquiry based on interactive computerized simulations, which enabled learners' active manipulation and analysis of their data, choosing their own path in learning, and advancing according to their preferred pace (Jacobson \& Wilensky, 2006; Landriscina, 2013); (b) the use of complementary multiple representations (verbal representations, equations, tables, graphs, and agents), which probably enhanced students' understanding of the represented phenomenon and their ability to translate and move freely among the different representations, as well as increasing their cognitive flexibility (Boulter \& Buckley, 2000); and (c) the use of two different representations of the same complex system (i.e., the SD and the AB simulations) and the requirement to compare between them, which enabled the construction of relations between the macro and micro levels of the system as well as a blend of deductive (top-down) and inductive (bottomup) reasoning for constructing both a zoomed-in close-up picture and a zoomed-out full picture of the complex system's operation. As usually is the case in classrooms, few students failed to achieve good conceptual understanding (and of equilibrium in particular), in spite of the curriculum scaffolding, expressed in their limited manifestations of system thinking, calling for additional improvement of this pilot curriculum.

The main study limitation is the lack of counterbalance design that hinders our ability to know if the order of exposure to the two different simulations is the preferred one, and the specific contribution of each simulation in this combined mode of learning. In addition, it is safe to assume that the first Phase gains promoted in part the second Phase gains. Finally, the study sample is of a medium to high SES, which is not representative of the general population of this age and participants' gender ratio is unbalance due to the elective nature of the course, thus may influence validity. However, most findings relate to students' different abilities to interpret their own manipulations of the systems, and we believe these may be relevant to any junior high school student. It may be possible that low achieving students may need more time, higher number and diversity of manipulation experiences and examples, or more detailed curriculum. Usually, teachers know their students and adapt the curriculum accordingly.

Future research should examine individual differences that may account for these different patterns of outcomes. For example, it may be necessary to increase the number of lessons devoted to each model and to carry out interdisciplinary science instruction in order for these less responsive middle-school students to acquire system thinking in depth. Further quantitative studies are necessary to examine the generalizability of the trends found here and to tease apart the possible differential effects of each of the two simulations and their combination in different sequences (a counterpart study), which is highly challenging to carry out in the authentic field. In addition, the current Complex Systems course was developed for teaching a relatively simple ecological system. To strengthen learners' knowledge and understanding, future science curricula should contain a large number of varied systems and more complex ones. Finally, although the current study's sample size was appropriate for this initial qualitative analysis, for some of the variables students only expressed a small number of relevant utterances, thereby limiting our ability to generalize the findings. Future studies would do well to implement similar interventions with larger samples.

In spite of this topic importance in the current era, complex systems structure and function still constitute a challenge for both teachers and students. The present study suggests a novel curriculum that as demonstrated here, improved students' understanding. We encourage other researchers to follow this line of research.

\section{References}

1. ActiveState (2007). Free Tcl open source binary language. Available: http://www.activestate.com/Products/activetcl/. 
2. M. Alfonseca, R. M.Carro, J. de Lara and E. Pudildo (1998). "Education in ecology at the internet with an object-oriented simulation language". In K. Juslin (Ed.), Proceeding of the EUROSIM'98 Simulation Congress at Espoo. Federation of European Simulation Societies, pp.118-123.

3. B. Eilam (2012). System thinking and feeding relations: Learning with a live ecosystem model. Instructional Science, 40(2), 213-239.

4. O. Ben-Zvi Assaraf and N. Orion (2010). "Four case studies, six years latter: Developing system thinking skills in junior high school and sustaining them over time". Journal of Research in Science Teaching, vol. 47, no. 10, pp. 1253-1280.

5. C. J. Boulter and B. C. Buckley (2000). "Constructing a typology of models for Science education". In J. K., Gilbert and J. C. Boulter (Eds.), Developing models in science education. Kluwer Academic Publishers, pp.46-47.

6. B. Brehmer (1992). "Dynamic decision making: human control of complex systems". Acta Psychologica, vol. 81, pp. 211-241.

7. B. C. Bucklet, J. D. Gobert, A. C. H. Kindfield, P. Horwitz, R. F. Tinker, B. Gerlits, U. Wilensky, C. Dede and J. Willet (2004). "Model-based teaching and learning with BioLogicaTM: What do they learn? How do they learn? What do we know"? Journal of Science Education and Technology, vol. 13 no.1, pp. 23-41.

8. E. S. Charles, \& S. d'Apollonia (2004). "Developing a conceptual framework to explain emergent causality: Overcoming ontological beliefs to achieve conceptual change". In K. Forbus, D. Gentner and T. Reiger (Eds.), Proceedings of the 26th annual cognitive science society. Lawrence Erlbaum Associates.

9. M. T. H. Chi (2005). "Commonsense conceptions of emergent processes: Why some misconceptions are robust". The Journal of the learning sciences, vol. 14 no. 2, pp. 161-199.

10.F. Draper (1993). "A proposed sequence for developing system thinking in a grades' 4-12 curriculum". System Dynamic Review, vol. 9, pp. 207-214.

11.J. W. Forrester (1992). "Policies and information sources for modeling". European Journal of Operational Research, vol. 59 no. 1, pp. 42-63.

12.J. B. Garfield and D. Ben-Zvi (2008). "Research on teaching and learning statistics". In J. B. Garfield and D. Ben-Zvi (Eds.), Developing students' statistical reasoning: Connecting research and teaching practice. Springer Science + Business Media B.V., pp. 21-43.

13.R. N. Giere (1999). "Using models to represent reality". In: L. Magnani and N. J. Nersessian (Eds.), Model based reasoning in scientific discovery. Kluwer Academic/Plenum Publishers., pp. 40-57.

14.J. K. Gilbert and R. Justi (2016). Modelling-based teaching in science education. Springer.

15.R. Golan Duncan and B. J. Reiser (2007). "Reasoning across ontologically distinct levels: Students' understandings of molecular genetics". Journal of Research in Science Teaching, vol. 44, no. 7, pp. 938-959.

16.R. L. Goldstone (2006). "The complex systems see change in education". Journal of the Learning Sciences, vol. 15, no. 1 , pp. 35-43.

17.R. L. Goldstone and Y. Sakamoto (2003). "The transfer of abstract principles governing complex adaptive systems". Cognitive Psychology, vol. 46, pp. 414-466.

18.R. Goldstone and J. Y. Son (2005). "The transfer of scientific principles using concrete and idealized simulations". Journal of the Learning Sciences, vol. 14, pp. 69-110.

19.M. E. Hinton and M. B. Nakhleh (1999). "Students' microscopic, macroscopic, and symbolic representations of chemical reactions". The Chemical Educator, vol. 4, no. 4, pp. 1-29.

20.C. E. Hmelo-Silver (2004). "Problem-based learning: What and how do students learn"? Educational Psychology Review, vol. 16, pp. 235-266.

21.C. E. Hmelo-Silver, D. L. Holton and J. L. Kolodner (2000). "Designing learning about complex systems". Journal of the Learning Science, vol. 9, pp. 247-298.

22.M. J. Jacobson (2001). "Problem solving, cognition, and complex systems: Differences between experts and novices". Complexity, vol. 6, no.3, pp. 41-49.

23.M. J. Jacobson and U. Wilensky (2006). "Complex systems in education: Scientific and educational importance and implications for the learning sciences". Journal of the Learning Sciences,vol. 15, no. 1, pp. 11-34.

24.M. J. Jacobson, M. Kapur and P. Reimann (2014). "Toward a complex systems meta-theory of learning as an emergent phenomenon: Beyond the cognitive versus situative debate". In J. L. Polman, E. A. Kyza, D. K. O'Neill, I. Tabak, W. R. Penuel, A. S. Jurow, K. O'Connor, T. Lee and L. D'Amico (Eds.), Learning and 
becoming in practice: The International Conference of the Learning Sciences (ICLS) 2014, Volume 1. International Society of the Learning Sciences., pp. 362-369.

25.M. J. Jacobson, M. Kapur, H-J. So and J. Lee (2011). "The ontologies of complexity and learning about complex systems". Instructional Science, vol. 39, pp. 763-783.

26.S. Kauffman (1995). At home in the universe: The search for laws of self-organization and complexity. Oxford University Press.

27.F. Landriscina (2013). Simulation and learning. A model-centered approach. Springer.

28.T. S. Levy and U. Wilensky (2008). "Inventing a "mid-level" to make ends meet: Reasoning between the levels of complexity". Cognition and Instruction, vol. 26, pp. 1-47.

29.R. Lowe, W. Schnotz and T. Rasch (2011). "Aligning affordances of graphs with learning task requirements". Applied Cognitive Psychology, vol. 25, pp. 452-459.

30.E. B. Mandinach (1989). "Model-building and the use of computer simulation of dynamic systems". Journal of Educational Computing Research, vol. 5, pp. 221-243.

31.E. Moxnes (2000). "Not only the tragedy of the commons: Misperceptions of feedback and policies for sustainable development". System Dynamics Review, vol. 16 no. 4, pp. 325-348.

32.N. J. Nersessian (1999). "Model based reasoning in conceptual change". In L. Magnani and N. J. Nersessian (Eds.), Model based reasoning in scientific discovery. Kluwer Academic/Plenum, pp. 5-22.

33.E. Norling (2007). "Contrasting a system dynamics model and an agent-based model of food web evolution". In L. Autunes and K. Takadama (Eds.), LNAI 4442. Springer-Verlag, pp. 57-68.

34.J. Ossimitz (1997). "The development of systems thinking skills using system dynamics modeling tools." Available: http://wwwu.uni-klu.ac.at/gossimit/sdyn/gdm_eng.htm.

35.H. V-D. Parunak, R. Savit and R. L. Riolo (1998). "Agent-based modeling vs. equation-based modeling: A case study and users' guide". In J. S. Sichman, R. Conte and N. Gilbert (Eds.), Multi-Agent Systems and AgentBased Simulations. Springer-Verlag, pp. 10-25.

36.S. K. Reed (2010).Thinking visually. Psychology Press. Taylor \& Francis Group.

37.M. Resnick and U. Wilensky (1998). "Diving into complexity: Developing problematic decentralized thinking through role-playing activities". The Journal of the Learning Sciences, vol. 7, pp. 153-172.

38.Y. Rogers and M. Scaife (1998). "How can interactive multimedia facilitate learning"? In J. Lee (Ed.), Intelligence and multimodality in multimedia interface: Research and applications. Association for the Advancement of Artificial Intelligence Press, pp. 34.

39.R. J. Spiro, J. C. Jehng (1990). "Cognitive flexibility and hypertext: Theory and technology for non-linear and multi-dimensional traversal of complex subject-matter". In D. Nix and R. J. Spiro (Eds.), Cognition, education and multi-media: Exploring ideas in high technology. Lawrence Erlbaum, pp. 163-205.

40.M. Steiff and U. Wilensky (2003). "Connected chemistry: incorporating interactive simulations into the chemistry classroom". Journal of Science Education and Technology, vol. 12,pp. 285-302.

41.M. Steiff, M. Hegarty and G. Deslongchamps (2011). "Identifying representational competence with multirepresentational displays." Cognition and Instruction, vol. 29, no, 1, pp. 123-145.

42.J. D. Sterman (2000). Business dynamics: systems thinking and modeling for a complex world. Irwin/McGrawHill.

43.K. Thompson and P. Reinmann (2010). "Pattern of use of an agent-based model and a system dynamics model: The application of patterns of use and the impacts on learning outcomes". Computer \& Education, vol. 54, pp. 392-403.

44.T. Vachliotis, K. Salta and C. Tzougraki (2014). "Meaningful understanding and system thinking in organic chemistry: Validating measurement and exploring relationships". Research in Science Education, vol. 44, pp. 239266.

45.J. J. G. Van Merrienboer, P. A. Kirschner and L. Kester (2003). "Taking the load off a learner's mind: instructional design for complex learning. Educational Psychologist. 38 (1), 5-13.

46.Verhoeff, R. P., Waarlo, A. J., \& Boersma, K. T. (2008). Systems modeling and the development of coherent understanding of cell biology". International Journal of Science Education, vol. 30, pp. 543-568.

47.U. Wilensky and K. Reisman (2006). "Thinking like a wolf, a sheep, or a firefly: Learning biology through constructing and testing computational theories - An embodied modeling approach". Cognition and Instruction, vol. 24 , no. 2, pp. 171-209. 
48.U. Wilensky and M. Resnick (1999). "Thinking in levels: A dynamics systems approach to making sense of the world". Journal of Science Education and Technology, vol. 8, no. 1, pp, 3-19.

49.U. Wilensky and W. Stroup (2002). "Participatory simulations: Envisioning the networked classroom as a way to support systems learning for all". Paper presented at the annual meeting of the American Educational Research Association. New Orleans, LA.

\section{Appendix}

\section{Pre and Posttest Problem: The Water Pool}

An increase in the water surface area of a pool increases evaporation.

A steady flow of water into a pool causes the water level to rise. Equilibrium is reached at a certain water level height,

a) How can you define this height?

b) What happens when the water flow into both pools increases?

Which of the following pool water levels (pool A, or pool B) has a higher probability of reaching equilibrium and therefore would be defined as a more stable pool?

Please explain your answer.

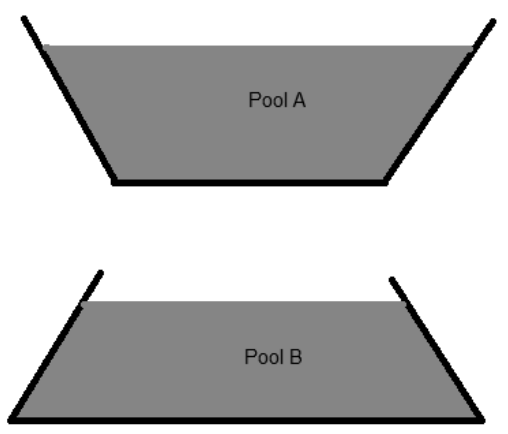

The correct answers:

a) The evaporation rate depends on the water surface area, which, in these pools, depends on the water level, due to their shapes. Both pools reach equilibrium when the evaporation rate (negative flow) equals the positive flow of water into the pool. Hence, the water level can be calculated.

b) We begin with a situation in which both pools' water levels are in an equilibrium state as evaporation equals water flow into the pool. Reaching an equilibrium level depends on the reaction of the pool to adding or subtracting a small amount of water from the pool.

1) In pool A, adding a small amount of water increases the water surface area. Thus, the evaporation rate also increases, bringing the water level back to its former equilibrium level. Therefore, pool A is relatively stable.

2) In pool B, adding a small amount of water decreases the water surface area. Consequently, the evaporation rate also decreases, pushing the water level higher. Moreover, this process enhances itself until the water overflows the pool. Therefore, pool $\mathrm{B}$ is less stable than pool A. 